\title{
Heat storage in forest biomass improves energy balance closure
}

\author{
A. Lindroth, M. Mölder, and F. Lagergren \\ Lund University, Geobiosphere Science Centre, Physical Geography and Ecosystems Analysis, Sölvegatan 12, \\ 22362 Lund, Sweden
}

Received: 29 June 2009 - Published in Biogeosciences Discuss.: 31 August 2009

Revised: 21 December 2009 - Accepted: 7 January 2010 - Published: 21 January 2010

\begin{abstract}
Temperature measurements in trunks and branches in a mature ca. 100 years-old mixed pine and spruce forest in central Sweden were used to estimate the heat storage in the tree biomass. The estimated heat flux in the sample trees and data on biomass distributions were used to scale up to stand level biomass heat fluxes. The rate of change of sensible and latent heat storage in the air layer below the level of the flux measurements was estimated from air temperature and humidity profile measurements and soil heat flux was estimated from heat flux plates and soil temperature measurements. The fluxes of sensible and latent heat from the forest were measured with an eddy covariance system in a tower. The analysis was made for a two-month period in summer of 1995. The tree biomass heat flux was the largest of the estimated storage components and varied between 40 and $-35 \mathrm{~W} \mathrm{~m}^{-2}$ on summer days with nice weather. Averaged over two months the diurnal maximum of total heat storage was $45 \mathrm{~W} \mathrm{~m}^{-2}$ and the minimum was $-35 \mathrm{~W} \mathrm{~m}^{-2}$. The soil heat flux and the sensible heat storage in air were out of phase with the biomass flux and they reached maximum values that were about $75 \%$ of the maximum of the tree biomass heat storage. The energy balance closure improved significantly when the total heat storage was added to the turbulent fluxes. The slope of a regression line with sum of fluxes and storage as independent and net radiation as dependent variable, increased from 0.86 to 0.95 for half-hourly data and the scatter was also reduced. The most significant finding was, however, that during nights with strongly stable conditions when the sensible heat flux dropped to nearly zero, the total storage matched the net radiation very well. Another interesting result was that the mean energy imbalance started to increase when the Richardson number became more negative than ca. -0.1 . In fact, the largest energy deficit occurred at
\end{abstract}

Correspondence to: A. Lindroth (anders.lindroth@nateko.lu.se) maximum instability. Our conclusion is that eddy covariance measurements can function well during stable conditions but that the functioning under strong instabilities might be a so far unforeseen problem.

\section{Introduction}

Flux measurements by eddy correlation (covariance) method in different types of ecosystems have become a standard method today (e.g., Aubinet et al., 2000). There are about 500 flux towers in use today in the different flux networks spread all over the world (available at: http://www.fluxnet. ornl.gov/fluxnet/, access: 25 June 2009). The main focus in most of these studies today is on carbon fluxes but all systems normally also measure the energy fluxes.

A general problem for many of these measurement sites is the lack of closure of the energy balance (McCaughey et al., 1997; Wilson et al., 2002; Barr et al., 2006). Since the measurement of turbulent fluxes of energy and $\mathrm{CO}_{2}$ is based on similar theoretical assumptions, it has been discussed that if the energy fluxes are biased then the $\mathrm{CO}_{2}$ could be biased too (Massmann and Lee, 2002; Twin et al., 2002; Wilson et al., 2002; Barr et al., 2006; Tanana et al., 2008). Specifically in these studies, it has been found that the energy balance closure is dependent on the friction velocity $\left(\mathrm{u}^{*}\right)$, the closure being better at higher friction velocities. However no firm relationships between the energy balance closure and the underestimation of $\mathrm{CO}_{2}$ flux has been established.

Although Halldin and Lindroth (1994) found significant differences between different types of net radiometers, the problems in turbulent flux measurements are today thought to be responsible for the lack of closure in the energy balance. Both high and low frequency losses in measurements are often discussed in this context. These kinds of corrections are still extremely problematic (Massman and Lee, 2002). Wolf et al. (2008) found that path-length averaging effect was

Published by Copernicus Publications on behalf of the European Geosciences Union. 
important for the open-path gas analyzer at a low height over short vegetation. Damping of the water vapour fluctuations in a tube of a closed-path system can also be considerable (Oliphant et al., 2004). But high frequency losses are generally expected to be less at tall forest sites (Wilson et al., 2002). On other hand, Foken et al. (2006) found that the energy imbalance was correlated with the low frequency part of the flux contribution. It would be desirable to increase the normal $30 \mathrm{~min}$ averaging time of calculation. Such an increase up to $2 \mathrm{~h}$ resulted in an improvement in the study by Cava et al. (2008). But Oliphant et al. (2004) show only a minor effect when increasing the averaging time and Barr et al. (2006) are concerned that prolongation of the averaging time will cause of other complications.

Advection could be another cause of the lack of energy balance closure (Lee, 1998; Paw et al., 2000; Massman and Lee, 2002, Wilson et al., 2002). Not only horizontal but also vertical advection could be important. The latter could be considerable during nighttime when non-zero vertical velocity is combined with large scalar gradients. However, today there is no strong evidence that advection is causing the problem with lack of energy balance closure (e.g., Foken, 2008).

Other uncertainties are related to the measurement of the soil heat flux and the storage of energy between the soil surface and the level of flux measurement. The latter become increasingly significant in tall vegetation like forests.

There are a few studies dealing with the estimation of heat storage in biomass (Aston, 1985; Moore and Fisch, 1985; McCaughey and Saxton, 1988; Meesters and Vugts, 1996; dos Santos Michiles and Gielow, 2008). One general conclusion is that this storage component can constitute a highly significant proportion of the net radiation during specific periods. For instance, Moore and Fisch (1985) found total heat storage fluxes in the order of $80 \mathrm{~W} \mathrm{~m}^{-2}$ in a tropical forest with a high biomass content per unit of ground area. Apparently, such high fluxes should also have implications for energy balance closure problem. The estimation of the biomass storage is very complicated because of the varying temperature in the tree stems. It requires a large number of sensors (McCaughey and Saxton, 1988; Oliphant et al., 2004; Barr et al., 2006; Rousant et al., 2006) or a sophisticated mathematical framework (Moore and Fish, 1985; Meesters and Vugts, 1996).

The aim of this paper is to quantify the energy balance components as accurately as possible with special emphasize on the heat storage in biomass, in a tall coniferous forest and to assess the energy balance closure problem on basis of these measurements.

The energy balance closure of our forest site has been analysed in another study by Moderow et al. (2009). But the present study is based on earlier data, when another flux system was used and more temperature measurements in tree trunks and branches were available for more detailed biomass storage analyses.

\section{Material and methods}

\subsection{Site and instrumentation}

Since June 1994, eddy-covariance and other meteorological measurements have been running continuously above a mixed spruce/pine stand at Norunda, about $30 \mathrm{~km}$ north of Uppsala, Sweden $\left(60^{\circ} 05^{\prime} \mathrm{N}, 17^{\circ} 28^{\prime} \mathrm{E}\right.$, alt. $\left.45 \mathrm{~m}\right)$. This longterm study was started as a Continuous Climate Monitoring within the framework of the NOPEX project (Lundin et al., 1999), and become later part of a number of collaborative projects within the EU concerning studies of the carbon balance of ecosystems (e.g., EUROFLUX, CARBOEUROFLUX, Carboeurope IP). This paper concerns the period 1 June-31 July in 1995 when biomass thermometers had been recently installed and all necessary data were available for the analysis.

Forests in that area, surrounding the tower, are mixtures of Norway spruce (Picea abies L., Karst.) and Scots pine (Pinus sylvestris L.). The soil is a deep, boulder-rich sandy glacial till. The area in the nearest $300-500 \mathrm{~m}$ around the $100-\mathrm{m}$ tower consists mainly of mature ca. 110-year-old stands (2004) dominated by pine. Outside of this area there are also stands of intermediate age classes, ca. 50-60-yearold stands, where spruce is dominant.

In the 110-years-old stand, the basal area was estimated $34.7 \mathrm{~m}^{2} \mathrm{ha}^{-1}$ and the maximum stand height was ca. $28 \mathrm{~m}$ in 1995. The stand is relatively open, with an emerging small understory of Norway spruce trees. The main canopy is composed of pine $(61.3 \%)$, spruce $(34.3 \%)$ and birch $(4.4 \%)$. The vegetation of the forest floor consists mainly of mosses and dwarf shrubs (Vaccinium myrtillus L.). The projected leaf area index (LAI) of this stand is 4-5 (Lundblad and Lindroth, 2001).

The region is quite level and homogeneous, with a maximum fetch of more than $20 \mathrm{~km}$ extending to the south-west (the most frequent wind direction) and a minimum fetch determined by a small lake at $1 \mathrm{~km}$ distance from the tower towards the north-north-west. At Uppsala, ca $30 \mathrm{~km}$ south of the site, the mean air temperature is $5.5^{\circ} \mathrm{C}(1961-1990)$; the mean annual precipitation is $527 \mathrm{~mm}$ and the mean Penman open water evaporation is $454 \mathrm{~mm}$.

\subsection{Flux measurements}

The eddy-correlation system that was mounted at $35 \mathrm{~m}$ height consisted of a SOLENT 1012R2 sonic anemometer (Gill Instruments, Lymington, UK) and a closed-path infrared gas analyser LI-6262 (LI-COR Inc., Lincoln, Nebraska, USA) as described by Grelle and Lindroth (1996). To minimize damping of high frequencies in the intake tubes, the entire system was mounted on the tower giving a tube length of ca. $6 \mathrm{~m}$. The air was sucked through the $4 \mathrm{~mm}$ inner diameter sampling tube at a flow rate of $8 \mathrm{~L} \mathrm{~min}^{-1}$. The high flow rate resulted in under pressure in the tube which prevented 
condensation to occur. Source area analyses indicate that measurements at $35 \mathrm{~m}$ height provide the best representation of the surrounding forest both during day- and night-time (Grelle, 1997). The calculation and correction of fluxes follows the EUROFLUX methodology (Aubinet et al., 2000). The gas analyser was calibrated for $\mathrm{H}_{2} \mathrm{O}$ using a LI-610 dew point generator (LI-COR Inc., Lincoln, Nebraska, USA).

\subsection{Meteorological measurements}

Air temperature was measured with copper-constantan thermocouples, placed in ventilated radiation shields, mounted on $5.5 \mathrm{~m}$ long booms at $8.5,13.5,19,24.5,28,31.7,36.9$, $43.8,58.5,73,87.5$ and $100.6 \mathrm{~m}$ on the tower. For air humidity measurements, air was sucked from the same measurement levels through a high density polyethylene tube down to an equipment shed for analysis in a gas analyser (LI-6262, LI-COR, Inc., Lincoln, Nebraska, USA). All tubes were insulated, heated and of similar length. The gas analyser was run in absolute mode, where dry nitrogen gas was vented at a very low rate through its reference cell. The profile system has been described in detail by Mölder et al. (2000). Net radiation was measured with a ventilated radiometer (LXV055, Dr Bruno Lange, Hamburg, Germany) mounted at $68 \mathrm{~m}$ height on the tower. The relatively high mounting of the net radiometer, ca. $40 \mathrm{~m}$ above the canopy top, means that the source area of the net radiation is fairly large. Following Schmid (1997), this would imply that $99 \%$ of the upwelling radiation received by the radiometer would come from a circular area of ca. $450 \mathrm{~m}$ radius.

The soil heat flux was measured directly by three soil heat flux plates (HFT-1, REBS, Seattle, WA, USA) installed ca $6 \mathrm{~cm}$ below the soil surface. The storage above the flux plate (see below) was estimated calorimetrically by using data from four soil thermometers installed at $10 \mathrm{~cm}$ depth. The voltage signals from the sensors were measured and stored with data loggers (CR10; Campbell Scientific, Inc., Logan, USA) using a 10-min storage interval.

\subsection{Biomass temperature}

The biomass temperatures were measured with thermocouples made from copper/constantan wires. The last $10 \mathrm{~cm}$ of the sensors consisted of thin wires with a diameter of ca 0.1 $\mathrm{mm}$. They were inserted into the biomass at different depths by drilling a $1 \mathrm{~mm}$ diameter whole. The resin formed by the wood quickly sealed the holes. Temperature measurements in two trees, one pine and one spruce, were selected for the analysis. Temperatures were measured at different heights, azimuthal positions and depths in the stems and on a number of branches (Table 1). Temperatures at the same height and depth in the stem, but at different azimuth positions were averaged. Branch temperatures were averaged as well.

\subsection{Heat storage in biomass}

Basically the methodology given by Meesters and Vugts (1996) has been used to calculate the storage change in biomass. First we consider a simple case of a sinusoidal temperature wave. Next the results will be generalised for an arbitrary temperature wave that can be presented by means of Fourier series. All the time series are given in complex form.

Sinusoidal temperature variations in the tree stem, at a distance of $r$ from stem axis, are:

$\Delta T_{r}(t)=T^{*} \exp (i \omega t)$,

were the $\Delta$ symbol means that deviations from the mean are considered, $T^{*}$ is a complex coefficient that contains both amplitude and phase, $\omega$ is the angular frequency and $t$ is the time.

For storage change calculation, temperature on the stem surface is needed. But temperature is usually not measured on the surface, but inside the stem instead. Temperature on the stem surface of radius $R$ can be calculated from the measured temperature at $r$ :

$\Delta T_{R}(t)=\frac{\mu_{0}\left(\rho_{R}\right)}{\mu_{0}\left(\rho_{r}\right)} \exp \left[i\left(\theta_{0}\left(\rho_{R}\right)-\theta_{0}\left(\rho_{r}\right)\right)\right] \Delta T_{r}(t)$

Here $\rho_{r}=\sqrt{\frac{\omega}{K}} r$ and $\rho_{R}=\sqrt{\frac{\omega}{K}} R$ are the dimensionless coordinate and radius, respectively and $K$ is the heat diffusivity. The parameters $\mu$ and $\theta$ are related to Kelvin-Thomson functions and are defined in Meesters and Vugts (1996) and Abramowitz and Stegun (1965).

Storage change per unit ground area in stems is given as:

$S_{\text {stem }}(t)=M \omega C_{M} \alpha \exp \left[-i\left(\phi-\frac{\pi}{2}\right)\right] \Delta T_{R}(t)$,

where $M$ is the amount of biomass per unit ground area and $C_{M}$ is the specific heat capacity of biomass. The new variables $\alpha$ and $\phi$ that are functions of $\rho_{R}$ have been introduced by Meesters and Vugts (1996), where also their approximation formulas can be found.

An arbitrary temperature wave in the tree stem, at a distance of $r$ from stem axis, can be estimated by means of Fourier series:

$\Delta T_{r}(t)=\sum_{k=1}^{k_{\max }} T_{k}^{*} \exp \left(i \omega_{k} t\right)+\gamma t$,

where $T_{k}^{*}$ are the complex Fourier coefficients that contain both amplitudes and phases, $\omega_{k}$ are the angular frequencies, $k$ is the harmonic number and $\gamma$ is the trend between the starting and the end temperatures.

For this case, temperature on the stem surface of radius $R$ can be calculated from a temperature Fourier series at $r$ :

$$
\begin{aligned}
\Delta T_{R}(t) & =\sum_{k=1}^{k_{\max }} \frac{\mu_{0}\left(\rho_{R, k}\right)}{\mu_{0}\left(\rho_{r, k}\right)} T_{k}^{*} \exp \left[i \left(\omega_{k} t+\theta_{0}\left(\rho_{R, k}\right)\right.\right. \\
& \left.\left.-\theta_{0}\left(\rho_{r, k}\right)\right)\right]+\gamma t
\end{aligned}
$$


Table 1. Positioning of stem temperature sensors. All depth/height units in meters.

\begin{tabular}{|c|c|c|c|c|c|c|c|}
\hline Species & Height & Stem diameter & Depth & Bark thickness & Woody diameter & Depth under bark & Sensor azimuths \\
\hline \multirow[t]{7}{*}{ Pine } & 1.5 & 0.340 & 0.03 & 0.018 & 0.304 & 0.012 & $\mathrm{~N}, \mathrm{E}, \mathrm{S}, \mathrm{W}$ \\
\hline & & & 0.07 & & & 0.052 & $\mathrm{~N}, \mathrm{E}, \mathrm{S}, \mathrm{W}$ \\
\hline & 8.6 & 0.270 & 0.03 & 0.007 & 0.256 & 0.023 & $\mathrm{~N}, \mathrm{E}, \mathrm{S}, \mathrm{W}$ \\
\hline & & & 0.07 & & & 0.063 & $\mathrm{~N}, \mathrm{E}, \mathrm{S}, \mathrm{W}$ \\
\hline & 16.6 & 0.200 & 0.03 & 0.005 & 0.19 & 0.025 & \\
\hline & & & 0.07 & & & 0.065 & $\mathrm{E}, \mathrm{S}, \mathrm{W}$ \\
\hline & Branch & & & & & & 6 different \\
\hline \multirow[t]{3}{*}{ Spruce } & 1.2 & 0.210 & 0.07 & 0.008 & 0.194 & 0.062 & $\mathrm{~N}, \mathrm{~S}$ \\
\hline & 8.4 & 0.150 & 0.07 & 0.006 & 0.138 & 0.064 & $\mathrm{~N}, \mathrm{~S}$ \\
\hline & Branch & & & & & & near $\mathrm{N}, \mathrm{S}$ \\
\hline
\end{tabular}

Table 2. Species and fraction distribution in the investigated stand.

\begin{tabular}{|c|c|c|c|c|c|c|c|c|c|c|c|}
\hline Species & $\begin{array}{c}\text { Fraction } \\
\text { of dry } \\
\text { mass }(\%)\end{array}$ & Stems (\%) & $\begin{array}{c}\text { Needles } \\
\text { and live } \\
\text { branches } \\
(\%)\end{array}$ & $\begin{array}{c}\text { Dead } \\
\text { branches } \\
(\%)\end{array}$ & $\begin{array}{c}\text { Dry } \\
\text { density } \\
\left(\mathrm{kg} \mathrm{m}^{-3}\right)\end{array}$ & $\begin{array}{c}\text { Fresh } \\
\text { density } \\
\left(\mathrm{kg} \mathrm{m}^{-3}\right)\end{array}$ & $\begin{array}{c}\text { Stems } \\
\left(\mathrm{kg} \mathrm{m}^{-2}\right)\end{array}$ & $\begin{array}{l}\text { Needles } \\
\text { and live } \\
\text { branches } \\
\left(\mathrm{kg} \mathrm{m}^{-2}\right)\end{array}$ & $\begin{array}{c}\text { Dead } \\
\text { branches } \\
\left(\mathrm{kg} \mathrm{m}^{-2}\right)\end{array}$ & $\begin{array}{c}\text { Sum of } \\
\text { needles and } \\
\text { branches } \\
\left(\mathrm{kg} \mathrm{m}^{-2}\right)\end{array}$ & $\begin{array}{c}\text { Total fresh } \\
\text { mass } \\
\left(\mathrm{kg} \mathrm{m}^{-2}\right)\end{array}$ \\
\hline Pine & 61.3 & 89.3 & 9.2 & 1.4 & 430 & 900 & 24.07 & 2.49 & 0.18 & 2.68 & 26.74 \\
\hline Spruce & 34.3 & 68.2 & 30.0 & 1.8 & 400 & 825 & 10.13 & 4.45 & 0.13 & 4.58 & 14.71 \\
\hline Deciduous & 4.4 & & & & 455 & 900 & & & & & 1.90 \\
\hline Forest & 100 & & & & & & & & & & 43.35 \\
\hline
\end{tabular}

The dimensionless coordinate and radius become $\rho_{r, k}=$ $\sqrt{\frac{\omega_{k}}{K}} r$ and $\rho_{R, k}=\sqrt{\frac{\omega_{k}}{K}} R$, respectively.

When the temperature Fourier series is given on the stem surface then the storage change in stems is:

$$
S_{\text {stem }}(t)=M C_{M}\left\{\sum_{k=1}^{k_{\max }} \alpha_{k} \omega_{k} T_{k}^{*} \exp \left[i\left(\omega_{k} t-\phi_{k}+\frac{\pi}{2}\right)\right]+\gamma\right\}(6)
$$

But, when the temperature Fourier series is given inside the stem, then the storage change in stems is:

$$
\begin{aligned}
S_{\text {stem }}(t) & =M C_{M}\left\{\sum _ { k = 1 } ^ { k _ { \operatorname { m a x } } } \alpha _ { k } \omega _ { k } \frac { \mu _ { 0 } ( \rho _ { R , k } ) } { \mu _ { 0 } ( \rho _ { r , k } ) } T _ { k } ^ { * } \operatorname { e x p } \left[i \left(\omega_{k} t+\theta_{0}\left(\rho_{R, k}\right)\right.\right.\right. \\
& \left.\left.\left.-\theta_{0}\left(\rho_{r, k}\right)-\phi_{k}+\frac{\pi}{2}\right)\right]+\gamma\right\}
\end{aligned}
$$

Because branches have a small diameter, a constant temperature is assumed throughout the whole cross section. Needles are assumed to have the same temperature as branches. Thus, heat storage change in the branches and needles is:

$S_{\text {branch }}(t)=M C_{M}\left\{\sum_{k=1}^{k_{\max }} \omega_{k} T_{k}^{*} \exp \left[i\left(\omega_{k} t+\frac{\pi}{2}\right)\right]+\gamma\right\}$,

here $M$ is the mass of branches and needles per unit topographic area.
The necessary data on the amount of biomass were extracted from Håkansson and Körling (2002). The biomass calculations are summarised in Table 2. Firstly, the fraction of pine and spruce trees and the fraction of different tree compartments were known. All biomass calculations were made on the basis of dry mass. The average amount of dry biomass around the tower was $21 \mathrm{~kg} \mathrm{~m}^{-2}$. The dry mass was recalculated to wet mass using the densities from a (Swedish) handbook in forestry (Anonymous, 1994). Two classes, the stems and the needles and branches together were treated separately in the storage calculations. The sum of storage in pine and spruce trees was increased linearly by the amount of deciduous trees (divided by 0.956 ).

The pine tree, where the stem temperatures were measured, was divided into four compartments: three stem sections and the needles and branches together (Table 3). For the spruce tree, two stem sections were used in the analysis. We estimated the wet mass of each compartment of these trees. The storage was calculated for each compartment with its actual mass. This was scaled up to the stand level using the both the tree and the stand biomass data. For instance, the storage of a specific section of the pine stem was calculated as the mass of that stem section divided by the total stem mass of the tree and then multiplied by the mass of pine stems per unit ground in place of $M$ in (Eq. 7). The mass of stand needles and branches was used directly from Table 2 in place of $M$ in (Eq. 8) 
Table 3. Volume and fresh weight for the different stem segments.

\begin{tabular}{lllcccc}
\hline Species & $\begin{array}{l}\text { Height } \\
\text { interval }(\mathrm{m})\end{array}$ & $\begin{array}{l}\text { Volume } \\
\left(\mathrm{m}^{3}\right)\end{array}$ & $\begin{array}{c}\text { Fresh density } \\
\left(\mathrm{kg} \mathrm{m}^{-3}\right)\end{array}$ & $\begin{array}{c}\text { Mean radius } \\
\text { on bark }(\mathrm{m})\end{array}$ & $\begin{array}{c}\text { Mean radius } \\
\text { under bark }(\mathrm{m})\end{array}$ & Mass $(\mathrm{kg})$ \\
\hline Pine & $0-5$ & 0.409 & 900 & 0.163 & 0.148 & 367.9 \\
& $5-12$ & 0.350 & & 0.127 & 0.120 & 314.7 \\
& $12-26.4$ & 0.282 & & 0.093 & 0.088 & 253.8 \\
& Total & & & & & 936.5 \\
& & & & & & \\
Spruce & $0-5$ & 0.143 & 825 & 0.097 & 0.089 & 118.1 \\
& $5-18.7$ & 0.139 & & 0.066 & 0.060 & 114.8 \\
& Total & & & & & 232.9 \\
\hline
\end{tabular}

We used the same value of heat capacity $C_{M}=$ $2800 \mathrm{~J} \mathrm{~kg}^{-1} \mathrm{~K}^{-1}$ for all the different compartments, i.e. for pine and spruce and for stems, needles and branches. One necessary parameter is the heat diffusivity $K$. Based on the literature and their own data Meesters and Vugts (1996) suggested $K$ to be $1.4-2.0 \times 10^{-7} \mathrm{~m}^{2} \mathrm{~s}^{-1}$ for a broad range of tree types. Calculations are not very sensitive to $K$ because it enters the equations (see after (Eq. 5) under square root. We used the value of $1.5 \times 10^{-7} \mathrm{~m}^{2} \mathrm{~s}^{-1}$, except the $8.6 \mathrm{~m}$ height for pine, where $2.0 \times 10^{-7} \mathrm{~m}^{2} \mathrm{~s}^{-1}$ gave more similar surface temperatures when calculated from temperatures at two different depths.

The depths of the sensors were originally counted from the bark-surface, and the diameters were measured with the bark included. The thickness of the bark was taken into account using empirical data from the site for the thick bark at low levels and using estimated values for the thin bark at high levels. The measured radius at the sensor height was used for the transition from inside-stem temperature to the stem surface temperature. For calculation of the storage in the stem cylinder, the average radius of the cylinder was used. The two radiuses were close to each other, however.

To calculate the volume of the pine and the spruce, we used the following relationship for the stem shape:

$\frac{R}{R_{b}}=-2.298 \cdot\left(\frac{z}{h}\right)^{3}+3.018 \cdot\left(\frac{z}{h}\right)^{2}-1.825 \cdot\left(\frac{z}{h}\right)+1.087$,

where $R$ is the radius at height $z, R_{b}$ is the radius at breast height and $h$ is the tree height. This function was adjusted so that the integrated volume matched the volume calculated from $R_{b}$ and $h$ according to Näslund (1947).

The tree height (in $\mathrm{m}$ ) was related to the diameter, $D$, at breast height (in cm) as (Håkansson and Körling, 2002):

$h=9.0153 \cdot \ln (D)-5.3696$ for pine

and

$h=-0.00734 \cdot D^{2}+0.98677 \cdot D+1.3$ for spruce
The storage of each stem section was calculated using temperatures from two depths (see Table 1) (azimuthally averaged) and those storage values were then averaged. Storages of different stem sections (three for pine and two for spruce) were added to give total heat storage for the respective stems. Storage for needles and branches was evaluated separately. Here the measured and averaged temperature was assumed to be representative for the whole mass of the compartment. The sum of the stem and the branch/ needle storage gave the tree heat storage. The sum of the two tree types gave the stand storage.

The length of the studied period was 61 days; thus, this determined the lowest frequency in our Fourier analyses. Most of the Fourier series were calculated with $4 \times 61$ harmonics. To get somewhat smoother fittings, the Fourier series for the needles/branches were made with 160 harmonics.

\subsection{Heat storage in the soil}

Soil heat flux was measured with 4 soil heat flux plates at depth of $6 \mathrm{~cm}$. This measurement has to be corrected for heat storage between the plate and the soil surface. The closest depth to the surface where the soil temperature was measured was $10 \mathrm{~cm}$. At this depth temperature was measured in 8 points. The temperature from $10 \mathrm{~cm}$ was theoretically recalculated to a temperature at $3 \mathrm{~cm}$ depth, which is a depth exactly in the middle of the surface and the plate. This calculated temperature was used to calculate the heat storage above the plate.

Temperature in the soil, at a depth $z_{2}$ (in our case $10 \mathrm{~cm}$ ) is:

$\Delta T_{z_{2}}(t)=\sum_{k=1}^{k_{\max }} T_{k}^{*} \exp \left(i \omega_{k} t\right)+\gamma t$

Temperature at another depth $z_{1}$ (in our case $3 \mathrm{~cm}$ ) is:

$\Delta T_{z_{1}}(t)=\sum_{k=1}^{k_{\max }} T_{k}^{*} \exp \left(-\frac{z_{1}-z_{2}}{D_{k}}\right) \exp \left[i\left(\omega_{k} t-\frac{z_{1}-z_{2}}{D_{k}}\right)\right]+\gamma t$,

where $D_{k}=\sqrt{\frac{2 \omega_{k}}{a}}$ and $a$ is the soil heat diffusivity. 
If temperature at the depth $z_{1}$ is taken to represent the average temperature between the soil heat flux plate and the surface, then the storage in that layer is:

$$
\begin{aligned}
S_{\text {above }}(t)= & \Delta z \rho_{s} C_{s}\left\{\sum_{k=1}^{k_{\max }} T_{k}^{*} \omega_{k} \exp \left(-\frac{z_{1}-z_{2}}{D_{k}}\right) \exp \right. \\
& {\left.\left[i\left(\omega_{k} t-\frac{z_{1}-z_{2}}{D_{k}}+\frac{\pi}{2}\right)\right]+\gamma\right\}, }
\end{aligned}
$$

where $\Delta z=0.06 \mathrm{~m}$ is the thickness of the soil layer, $\rho_{s}$ is the density of soil and $C_{S}$ is the heat capacity of soil. The corrected ground heat flux is then:

$G=G_{\text {plate }}+S_{\text {above }}$

were $G_{\text {plate }}$ is measured by the plates. Measurements from four plates were averaged. Temperature in each point ( 8 all together) was fitted with the Fourier series and the storage correction was calculated. Then 8 storage corrections were averaged and added to the average of plates as shown by (Eq. 13).

We used the following parameters taken from Guyot (1998) for a dry, $40 \%$ porous sandy soil: density, $\rho_{s}=1600 \mathrm{~kg} \mathrm{~m}^{-3}$, heat capacity, $C_{s}=800 \mathrm{~J} \mathrm{~kg}^{-1} \mathrm{~K}^{-1}$ and heat diffusivity, $a=2.4 \times 10^{-7} \mathrm{~m}^{2} \mathrm{~s}^{-1}$. Again, the length of the period was 61 days. The number of harmonics in the Fourier series was $2 \times 61$.

We were forced to use this method in order to calculate the storage between the flux plates and the soil surface because we were lacking temperature measurements in that soil layer. This introduces some uncertainty which is not so easy to estimate. However, in one of the soil profiles the temperature was measured at $5 \mathrm{~cm}$ depth and since this level is much closer to centre of the top $6 \mathrm{~cm}$ level of the soil, we used this measurement to test how well our extrapolation from $10 \mathrm{~cm}$ was doing. Thus, we applied the above mentioned extrapolation method for both the $5 \mathrm{~cm}$ and $10 \mathrm{~cm}$ measured temperatures and found that the standard deviation of the difference in storage of these two estimates was $\pm 3 \mathrm{~W} \mathrm{~m}^{-2}$. Another uncertainty is consists of the uncertainty in the soil parameters, heat capacity and heat diffusivity, respectively. The top $6 \mathrm{~cm}$ of the soil consists of a mixture of mineral soil, organic material and water. The summer of 1995 was quite dry and the soil moisture was about $10 \%$ and, thus, this would increase both heat capacity and heat diffusivity as compared to a dry soil. On the other hand, a certain fraction of organic material would work in the other direction. We therefore used the dry mineral soil parameter values and we estimated that this gave an additional uncertainty of $\pm 2 \mathrm{~W} \mathrm{~m}^{-2}$. Thus, all together the estimated uncertainty in the top $6 \mathrm{~cm}$ storage term was $\pm 5 \mathrm{~W} \mathrm{~m}^{-2}$.

\subsection{Heat storage in the air}

Theoretically storage of sensible heat in the air below the eddy-correlation system is:

$S_{\text {sensible }}=\rho c_{p} \int_{0}^{z_{\text {sonic }}} \frac{\partial T}{\partial t} d z$,

and storage of latent heat (due to phase shifts in air water column) is:

$S_{\text {latent }}=\rho L \int_{0}^{z_{\text {sonic }}} \frac{\partial q}{\partial t} d z$

where $q$ is the specific humidity of air.

The eddy-correlation system was placed at $35 \mathrm{~m}$ height. For storage calculations, air temperatures and air humidities from seven heights $(8.5,13.5,19.0,24.5,28.0,31.7$ and $36.9 \mathrm{~m}$ ) were used. In the equations above, the differentials were replaced with finite differences and the integrations with summing. We calculated heat and humidity content in a column between 0 and $36.9 \mathrm{~m}$ by summing up the contents in the columns $0-8.5 \mathrm{~m}, 8.5-13.5 \mathrm{~m}, \ldots$, and $31.7-36.9 \mathrm{~m}$. The average temperature in the first column was taken equal to the temperature at $8.5 \mathrm{~m}$; in the column $8.5-13.5 \mathrm{~m}$ it was taken equal to the mean of temperatures at $8.5 \mathrm{~m}$ and $13.5 \mathrm{~m}$, and so on. Similarly was done with the water vapour content. These calculations were based on 30-min mean data, thus, the calculated heat and water vapour contents were representative for mid points for those $30 \mathrm{~min}$ periods, i.e. times $X X: 15$ and $X X: 45$. Then the storage values, calculated from the time differences were representative for periods centred on full and half hours (XX:00 and XX:30). To make them better match with the eddy-correlation data (centred around $\mathrm{XX}: 15$ and $\mathrm{XX}: 45$ ), a 15 min time shift using linear interpolation was made.

\subsection{Atmospheric stability}

Atmospheric stability is characterized by the Richardson number:

$R i=\frac{g}{T} \frac{\frac{\Delta \theta}{\Delta z}}{\left(\frac{\Delta u}{\Delta z}\right)^{2}}$,

where $\Delta \theta$ and $\Delta u$ are the potential temperature and wind speed differences between 43.8 and $28 \mathrm{~m}$, respectively, $g$ is the acceleration of gravity and $T$ is the average air temperature. The Richardson number was chosen because it is independent of the flux measurements and because it has a known critical value near 0.2 under stable conditions. 


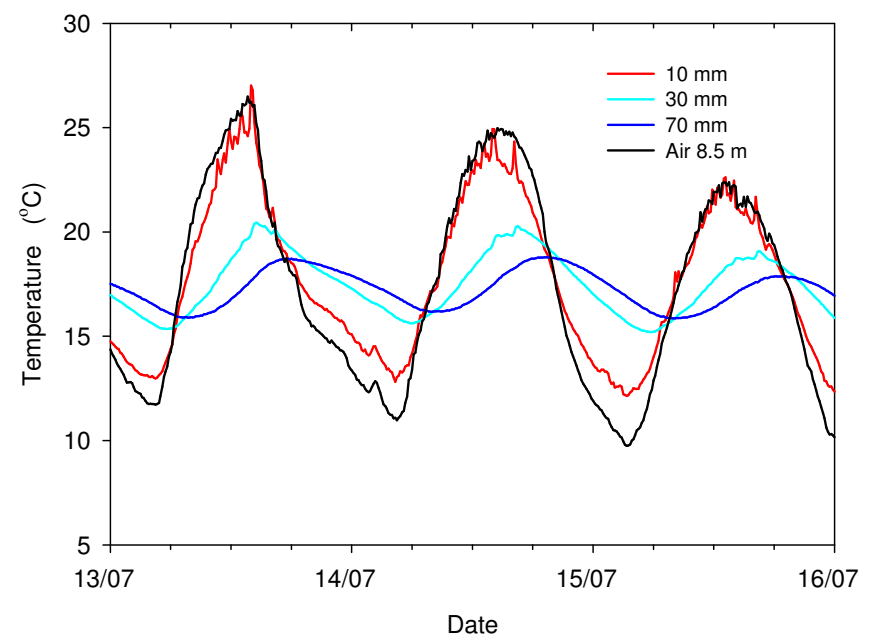

Fig. 1. The azimuthally averaged temperatures at different depths from the bark surface and inwards in the trunk of a pine tree at $8.6 \mathrm{~m}$ height above ground. Also shown is the air temperature at $8.5 \mathrm{~m}$ above ground. All values are 10-minute averages.

\section{Results}

\subsection{Biomass temperature}

The temperature in the trunk decreases rapidly from the bark surface and inwards (Fig. 1) with the largest gradient close to the trunk surface. The drop in maximum temperature between 10 and $30 \mathrm{~mm}$ depths is between 5-7 degrees during a sunny day. The difference in maximum temperature between the 30 and the $70 \mathrm{~mm}$ depths is much smaller, only in the order of one degree. The phase shift is also obvious with the $10 \mathrm{~mm}$ sensor reaching its maximum $1-2 \mathrm{~h}$ after noon while the $70 \mathrm{~mm}$ sensor reaches its maximum about $10 \mathrm{~h}$ later. It can also be noticed that the $10 \mathrm{~mm}$ temperature shows a much larger small-scale variation than those at larger depths in the trunk. We hypothesize that these small-scale variations are caused by variations in shaded respectively sun lit areas on the trunk surfaces caused by neighboring trees, since these were three clear days with smooth diurnal variation in incoming radiation (cf. Fig. 6) and, thus, also presumably a smooth variation in sap flow. The variation in the $10 \mathrm{~mm}$ depth temperature was also much smaller during nighttime supporting this hypothesis.

There is also a significant vertical gradient in mean (all directions) surface temperature along the trunk with increasing maximum temperatures with increasing height along the stem (Fig. 2). The difference in maximum surface temperature between the base of the tree $(1.5 \mathrm{~m})$ and the highest level in the canopy $(16.6 \mathrm{~m})$ is ca 7 degrees. At night, however, the difference in trunk surface temperature is much smaller, ca. 2 degrees, and with reversed order so that the highest level now is coolest. The branch surface temperature shows much larger amplitude than the top trunk surface, which is partic-

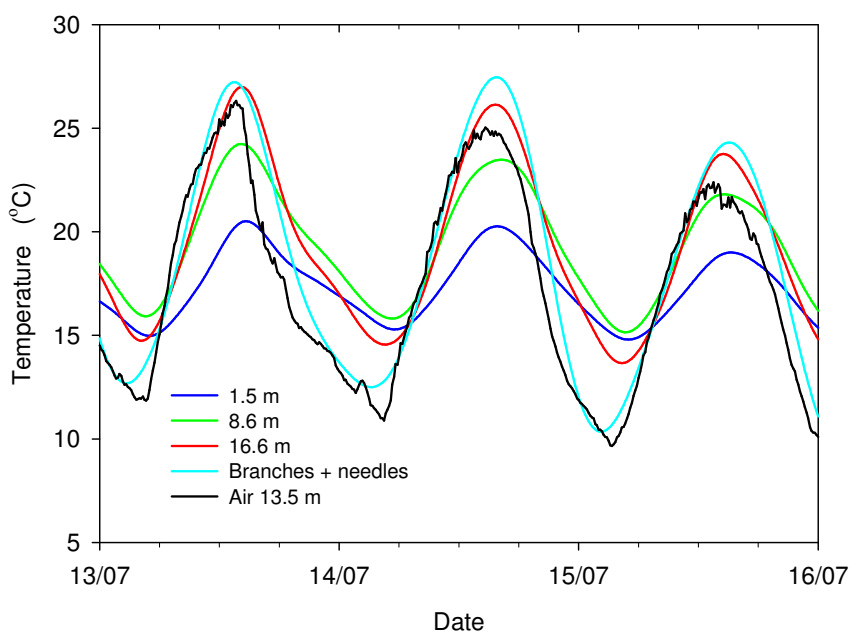

Fig. 2. The estimated trunk surface temperature at different heights along the trunk of a pine tree as well as the temperature of the branches and of the air.

ularly obvious at night when it cools 2 to 4 degrees more than the trunk surface. Both the branch surface temperature and the surface temperature of the highest trunk segment are 1-2 degree warmer than the air temperature at noon.

\subsection{Biomass heat storage}

Since the stand was dominated by pine and because we had more detailed temperature measurements in the pine, we selected that species to illustrate the heat storage variation in different sections of the biomass. In the up-scaling procedure it was assumed that the three trunk temperature measurement levels, $1.5,8.6$ and $16.6 \mathrm{~m}$, represented stem sections $0-5.5,5.5-12.6$ and $12.6-26.5 \mathrm{~m}$, respectively. This choice was made more or less arbitrarily. It turned out that the heat storage in the trunks was relatively constant in the vertical direction ranging between 0.55 and $0.67 \mathrm{~W} \mathrm{~m}^{-2}$ per meter vertical distance around noon. Thus, the shortest trunk segment $0-5.5 \mathrm{~m}$ contributed least to the trunk heat storage in pine trees while the top segment contributed most (Fig. 3). The lowest segment had its maximum a couple of hours later in the day as compared to the intermediate and highest segments. The branches and needles reached their maximum storage a couple of hours before noon with a maximum heat flux of ca $4 \mathrm{~W} \mathrm{~m}^{-2}$. The total storage flux in the pine trees peaked around noon and midnight with maximum and minimum values of +20 and $-20 \mathrm{~W} \mathrm{~m}^{-2}$, respectively.

When all species in the stand are taken into account, the total storage flux in the biomass ranges between +40 and $-35 \mathrm{~W} \mathrm{~m}^{-2}$ during these three days in July (Fig. 4). The maximum in branch and needle storage is about half of the maximum in the trunks and the branch plus needle storage peaks $2-3 \mathrm{~h}$ before the trunks. The maximum values shown here are also typical maximum values for the whole summer period (data not shown). 


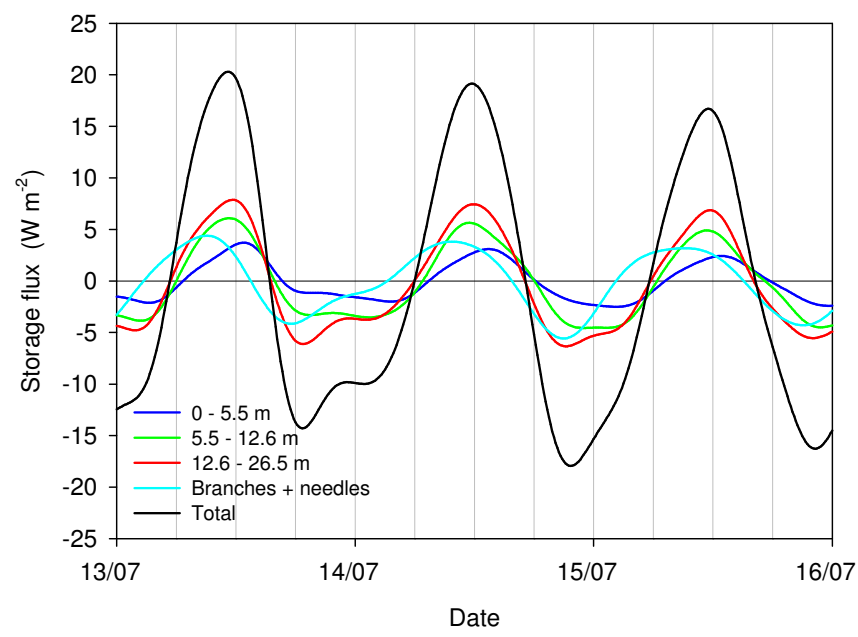

Fig. 3. The estimated biomass storage flux from different height intervals and the biomass storage flux from branches plus needles during the three summer days. The data shown here are scaled to the pine portion of the stand.

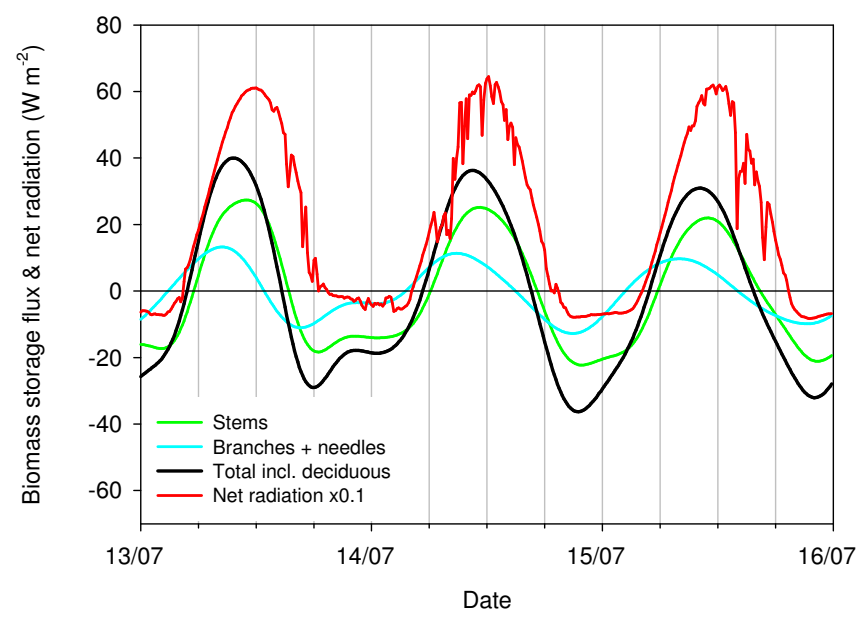

Fig. 4. The storage flux in the biomass of the entire stand divided into stem, branch plus needles and the total biomass storage flux during three summer days. Net radiation is also shown for comparison.

\subsection{Total heat storage and energy balance closure}

The mean diurnal curves for the peak summer months of June and July shows that the biomass storage flux is the largest of all components (Fig. 5) with a maximum flux of $22 \mathrm{~W} \mathrm{~m}^{-2}$. The soil heat flux and the sensible heat storage in the air below the flux measurement level, reaches about the same maximum values during daytime, ca. $15 \mathrm{~W} \mathrm{~m}^{-2}$ but with the former peaking around noon and the latter early in the morning. The latent heat storage is the smallest one and varies between a maximum of 5 to $6 \mathrm{~W} \mathrm{~m}^{-2}$ and a minimum of -7 to $-8 \mathrm{~W} \mathrm{~m}^{-2}$. The average total storage (including soil heat

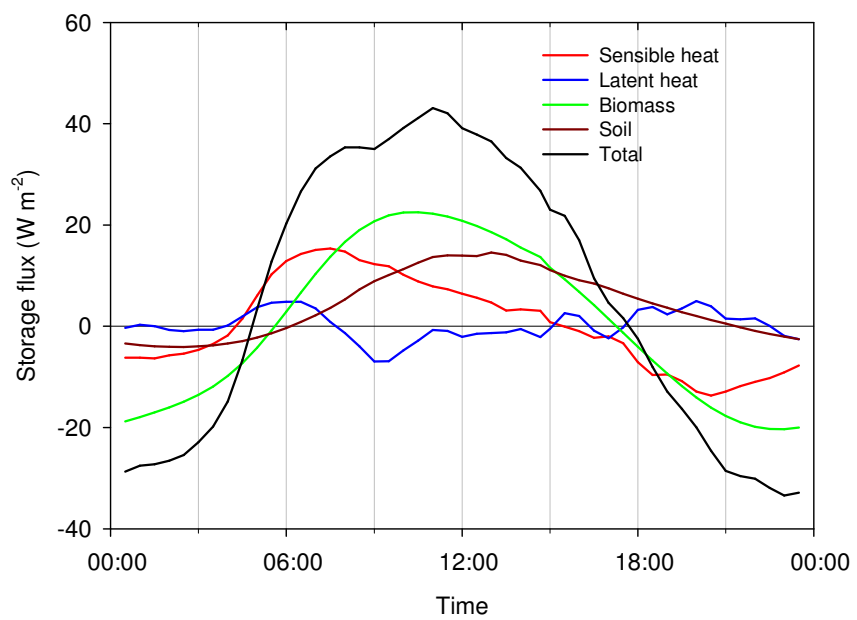

Fig. 5. The average storage flux during June-July 1995 divided into different components; the sensible and latent heat storage in stand air, the soil and the biomass, respectively.

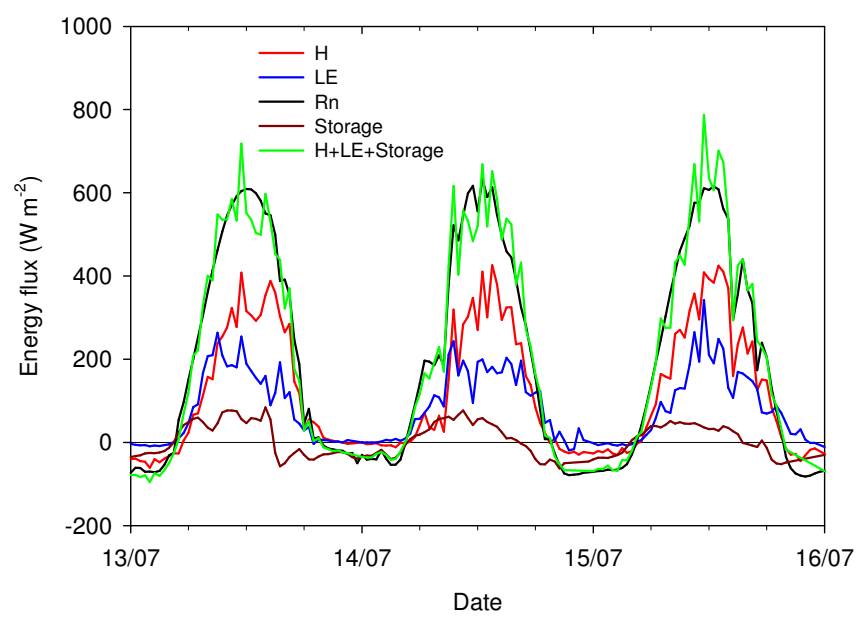

Fig. 6. Diurnal courses of all energy fluxes during three summer days.

flux) varies between ca 40 and $-35 \mathrm{Wm}^{-2}$. Because of the different time lags between the different storage components, the curve representing the total storage flux is slightly skewed towards the earlier part of the day (Fig. 5).

The effect of adding the total storage flux $(S)$ to the latent (LE) and sensible $(H)$ heat fluxes gives a significant improvement of closure. For the selected three day period, the sum of $H+\mathrm{LE}+S$ is in good agreement with the net radiation $\left(R_{n}\right)$ except that the larger variability in the turbulent fluxes is visible especially around noon (Fig. 6). The improvement is most obvious during nighttime and especially during the stable nights between 13 and 14 July and 14 and 15 July, respectively when the sensible and latent heat drop close to zero. The sensible heat flux reaches maximum values of about $400 \mathrm{~W} \mathrm{~m}^{-2}$ while the latent heat flux reaches 


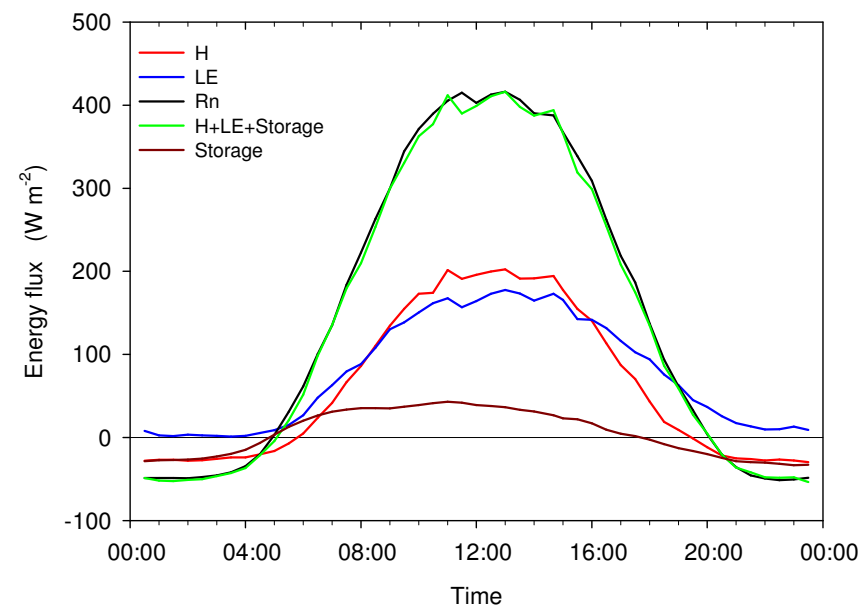

Fig. 7. The average diurnal course of the energy fluxes during June-July 1995.

$200-250 \mathrm{~W} \mathrm{~m}^{-2}$ during daytime for this period. The mean diurnal curve for the two summer months shows a striking agreement between $H+\mathrm{LE}+S$ and the net radiation (Fig. 7). The difference between $H$ and LE is much smaller when averaging the data over a two-month period. $H$ is only slightly larger then LE at noon, while LE is larger than $H$ both in the morning and in the afternoon. The storage flux is rather symmetric around noon but with a slight raise in the morning as compared to the afternoon.

One way of quantifying the energy balance closure over the whole range of variation in fluxes, is to plot the halfhourly vales of $H+\mathrm{LE}$ and $H+\mathrm{LE}+S$, respectively, versus the net radiation. The slope of the line should be 1 and the offset zero for a perfect closure. In our case, the slope increases from 0.857 to 0.975 and the offset decreases from +9.89 to $-2.28 \mathrm{~W} \mathrm{~m}^{-2}$ (Fig. 8). The scatter decreases when the total storage flux is added and, thus, $r^{2}$ increases. Most of the improvement in scatter can be seen in the lower range of the values.

\subsection{Energy balance closure in relation to stability}

We defined the energy "imbalance", with and without storage, as the difference between the net radiation $\left(R_{n}\right)$ and the sum of the respective fluxes $(H+\mathrm{LE}+S$ and $H+\mathrm{LE})$. We then sorted all data during the two month period into different classes of $R_{i}$ and calculated bin averaged values. The sorting was made such that there were equal number of values in each class, 100 for unstable conditions and 80 for stable conditions, respectively. For stable conditions the importance of the storage term increases with increasing stability (Fig. 9). The imbalance without storage reaches its maximum as $R_{i}$ approaches its critical value of 0.2 . The imbalance including the storage term is on average very small over the whole range of stable conditions (Fig. 9) with a tendency to a small

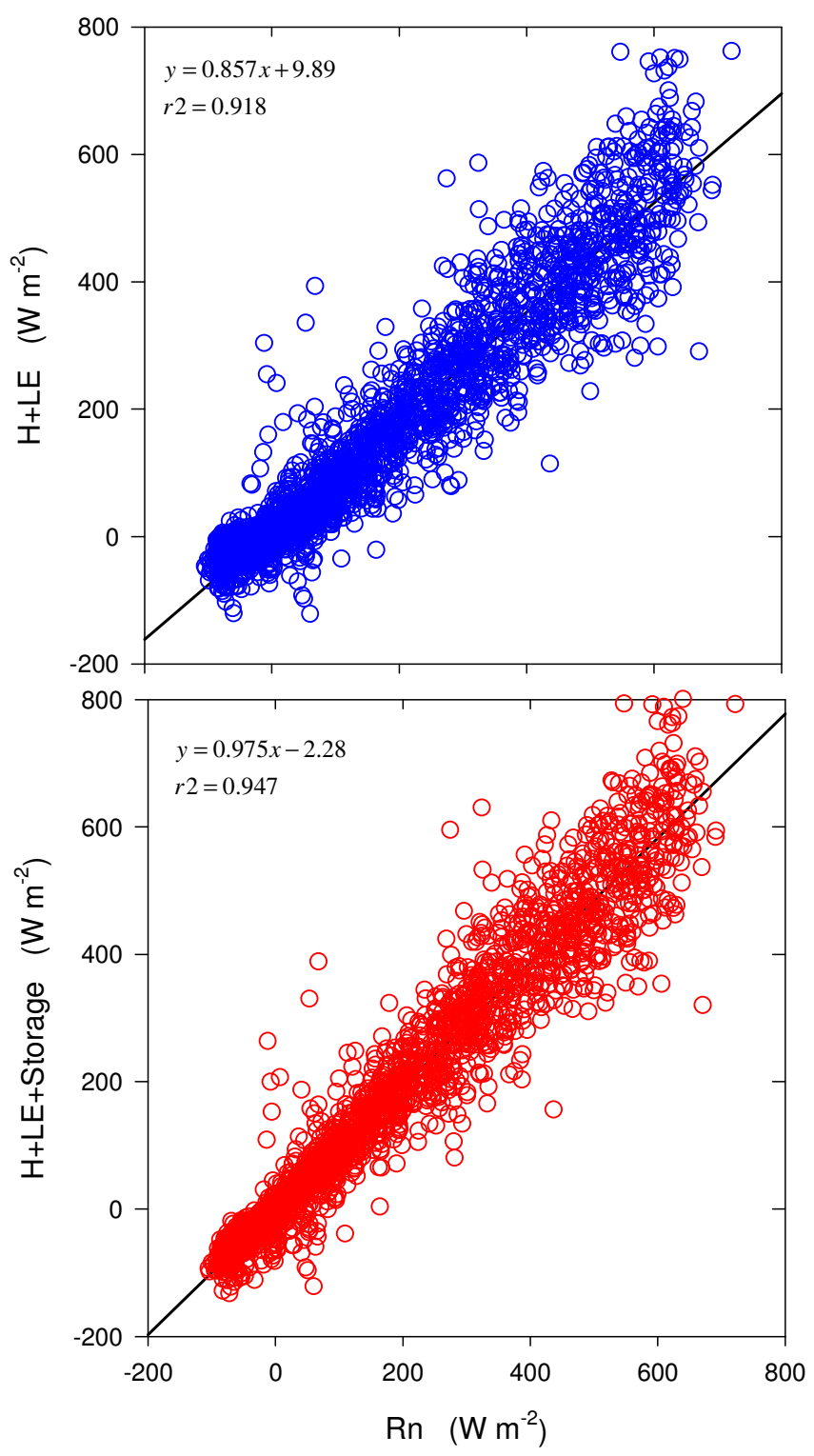

Fig. 8. The sum of the turbulent fluxes versus net radiation without (top) storage flux and with (bottom) the total storage flux included.

overestimation of fluxes for small $R_{i}$ and equally small underestimation at larger instabilities. The bin averaged imbalance including storage never exceeds $8-9 \mathrm{~W} \mathrm{~m}^{-2}$ over the whole range of stable conditions. The imbalance without storage increases steadily with increasing stability and decreasing sensible heat flux. The sensible heat flux decreases with increasing stability and start to approach zero when stability approaches $R_{i}=1$.

For unstable conditions the situation is quite different. The bin averaged imbalance with as well as without storage is small, less than $\pm 8 \mathrm{~W} \mathrm{~m}^{-2}$ for slightly unstable conditions $\left(R_{i}<\right.$ ca. -0.1$)$ and the imbalance with storage included continues to be small and of that order up to $R_{i}=-0.1$ (Fig. 10). 

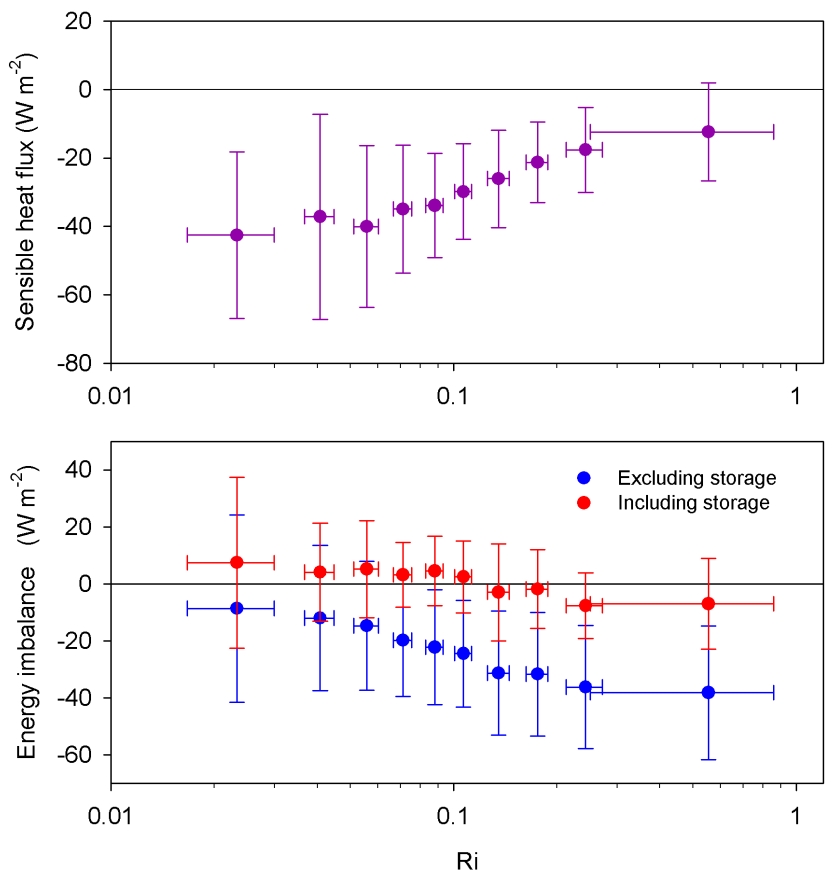

Fig. 9. Binned averages of sensible heat fluxes (top) and energy imbalance with and without storage (bottom) versus the Richadson number during stable conditions. Data from the whole period JuneJuly 1995. Some data points representing extreme stabilities have been discarded.

Both imbalance terms increases then more strongly, the more unstable the atmosphere becomes. It is interesting to note that the sensible heat fluxes first increases with increasing instability, reach a maximum around $R_{i}$ around $-0.1--0.2$ and then it decreases. The decrease in sensible heat fluxes at high instabilities seems to coincide with the increasing imbalance. The latent heat fluxes show exactly the same behviour (data not shown) although the magnitude of the latent heat fluxes are slightly smaller as compared to the sensible heat fluxes. Our interpretation is that it is an underestimation of the sensible and latent heat fluxes that causes the increase in imbalance at high instabilities and not an error in the storage term.

Plotting bin averaged energy imbalance with storage included against friction velocity separated into stable and unstable conditions (Fig. 11) shows some systematic patterns; during stable conditions and high friction velocity, the imbalance is slightly positive meaning that the sum of the fluxes exceeds the net radiation while it is the opposite at low friction velocities. The differences are however small although the largest imbalance occurs for the lowest friction velocity. The pattern is similar for unstable conditions with a small overestimation of the sum of the fluxes at high friction velocities and a somewhat larger underestimation at low friction velocities (Fig. 11).
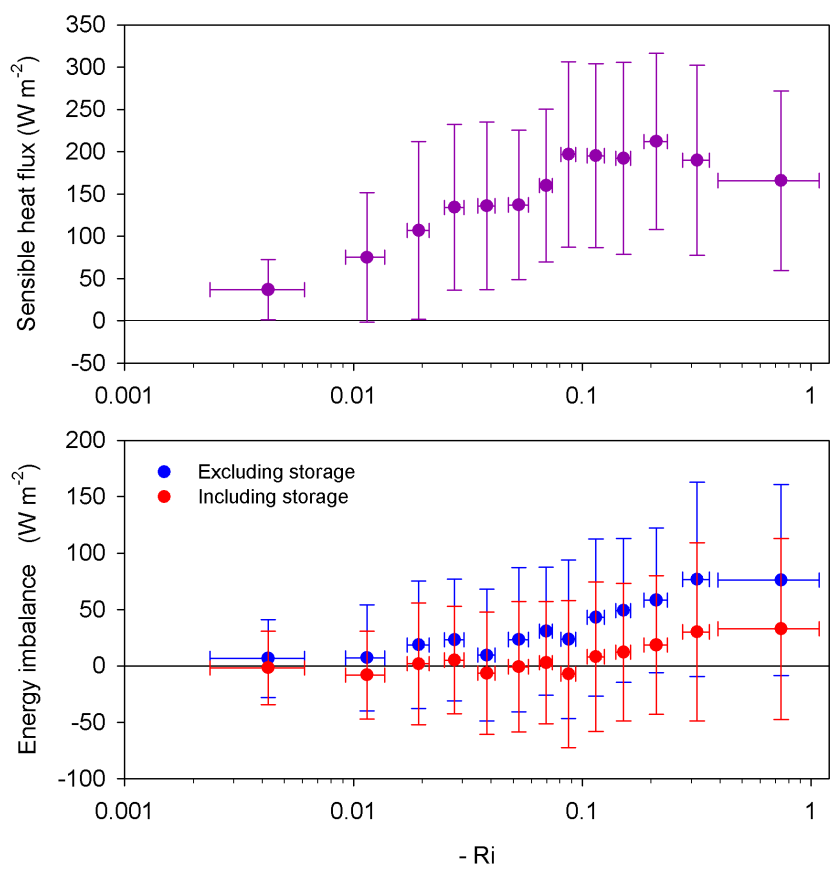

Fig. 10. Binned averages of sensible heat fluxes (top) and energy imbalance with and without storage (bottom) versus the Richadson number during unstable conditions. Data from the whole period June-July 1995. Data points representing extreme stabilities have been discarded.

\section{Discussion}

Our maximum total heat storage including biomass, air and soil is ca $40 \mathrm{~W} \mathrm{~m}^{-2}$. Other studies in forest have shown values up to $80-90 \mathrm{~W} \mathrm{~m}^{-2}$ (Moore, 1986; dos Santos Michiles and Gielow, 2008) and in some cases even up to $100 \mathrm{~W} \mathrm{~m}^{-2}$ (McCaughey and Saxton, 1988; Tanaka et al., 2008). The main storage components are soil, air and biomass with approximately equal contributions, though with phase lags between the components. The differences in maximum heat storage is not correlated with biomass density; a tropical rainforest with a biomass density of $60 \mathrm{~kg} \mathrm{~m}^{-2}$ (dos Santos Michiles and Gielow, 2008) had for instance similar maximum total storage fluxes as a young Siberian larch forest with a biomass density of $18 \mathrm{~kg} \mathrm{~m}^{-2}$ (Tanaka et al., 2008). The reason for this is probably because the rate of change of storage is largely determined by the rate of change of temperature which in turn is determined by the climatology of the site.

It is interesting to note that so few studies have been done where all storage components have been carefully estimated particularly in the light of the problems with closure of the energy balance which is of prime concern for the flux community (e.g., Wilson et al., 2002). It has been hypothesized (e.g., Barr et al, 2006) that the so called night time problem (e.g., Aubinet et al., 2000) is linked to the closure problem of the energy balance but so far no conclusive results have 

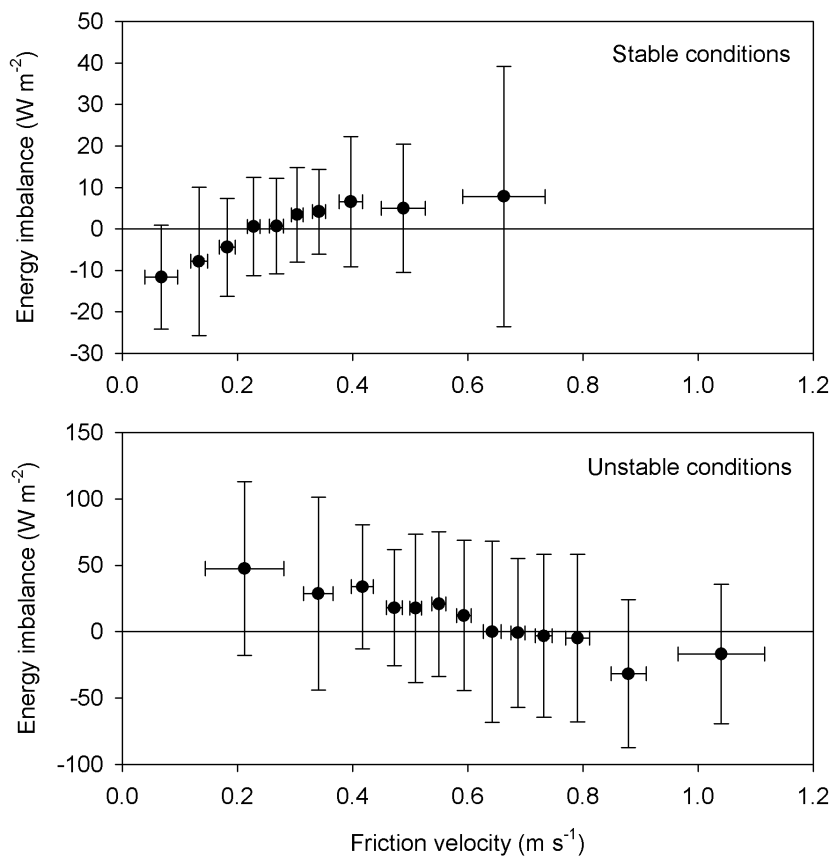

Fig. 11. Binned averages of energy imbalance including storage versus friction velocity during night (top) and day (bottom), respectively. Notice the difference in scales.

been found. Barr et al. (2006) found some similarities between the relationship between friction velocity and nighttime $\mathrm{CO}_{2}$ fluxes on one hand and between friction velocity and closure fraction $(H+\mathrm{LE}) /\left(R_{n}-\right.$ Storage $)$ of the energy balance on the other leading them to conclude that neither fluxes of $\mathrm{CO}_{2}$ nor fluxes of sensible and latent heat were correct during nighttime. Our result does not lend much support such a conclusion; the biomass storage component turned out to be particularly important during stable conditions and the closure was quite good over the whole range of stable conditions (cf. Fig. 9). However, we also noticed that there is a small systematic shift from overestimation to underestimation of fluxes with decreasing friction velocity during stable conditions (Fig. 11). The absolute difference is quite small, going from and overestimation of $+8 \mathrm{~W} \mathrm{~m}^{-2}$ to an underestimation of $-12 \mathrm{~W} \mathrm{~m}^{-2}$, when at the same time the friction velocity decreases from ca $0.65 \mathrm{~m} \mathrm{~s}^{-1}$ to $0.06 \mathrm{~m} \mathrm{~s}^{-1}$. This means that the relative imbalance is more significant since the magnitude of the fluxes is quite small during these conditions.

It was unexpected that the day-time energy imbalance should increase with increasing instability (cf. Fig. 10). The decrease in sensible heat flux at high instability, which coincides with an increase in imbalance indicates that the eddy covariance flux is underestimated during such conditions. This is also seen in the plot of energy imbalance versus friction velocity were the imbalance is increasing with decreasing friction velocity (Fig. 11). Barr et al. (2002) found similar behavior. Their closure fraction decreased with decreasing friction velocity which is the same as to say that the imbalance is increasing. This phenomenon has not been noticed very much before but it indicates that there might be a problem with eddy covariance measurements during strong instabilities which probably then also holds true for $\mathrm{CO}_{2}$ flux measurements.

There are a large number of hypotheses attempting to explain the inability of most eddy-covariance flux measurements to close the energy balance. Foken (2008) discusses several of them and his conclusion is that it is a scale problem related to the heterogeneity of the landscape which causes large eddies to develop. Large eddy simulations are powerful tools to analyse such processes and Kanda et al. (2004) used such simulations to assess the closure problem. They found a strong dependency between geostrophic wind speed and imbalance with increasing imbalance for decreasing wind speed. In their experimental set up it was assumed that the surface heat flux was constant $=0.1 \mathrm{Km} \mathrm{s}^{-1}$, i.e., they were simulating unstable conditions. This is consistent with our results that show that the imbalance is increasing with decreasing friction velocity under unstable conditions (Fig. 11).

Kanda et al. (2004) also analysed vertical flux divergence and concluded that this could also be important, especially for larger height differences which are particularly relevant for air craft measurements but typically not for near-surface measurements. However, since we measured the energy fluxes also at $70 \mathrm{~m}$ with an identical eddy covariance system as the one at $35 \mathrm{~m}$ level, we could asses this issue as well; we found that the sensible heat flux divergence was in the order of $0.5-0.7 \mathrm{~W} \mathrm{~m}^{-2} \mathrm{~m}^{-1}$ after correction for storage between 35 and $70 \mathrm{~m}$. Thus, it could explain deviations in the order of $7-10 \mathrm{~W} \mathrm{~m}^{-2}$ if we assume that the main source of the turbulent fluxes is located at ca. $20 \mathrm{~m}$ height above ground. The vertical sensible heat flux divergence was practically constant across the whole range of stabilities, so it could not explain the increase of imbalance at high instabilities. The latent heat flux showed no divergence with height.

Another possible explanation is that it is a measurement error related to the sonic anemometer. Gash and Dolman (2003) show that the angle of attack of the wind vector increases with increasing instability and that it is particularly large above forests. The sonic anemometer used here, the Gill R2, was tested in a wind-tunnel and a modified algorithm for flow distortion correction was applied (Grelle and Lindroth, 1994) but this algorithm was developed only for attack angles up to $10^{\circ}$. Van der Molen et al. (2004) showed that the vertical velocity was underestimated by about $15 \%$ for attack angles of $\pm 60^{\circ}$. Gash and Dolman (2003) estimated the theoretical attack angle as a function of stability and strongly unstable condition corresponding to $R_{i}=-1$ the attack angle could be in the order of $\pm 40^{\circ}$. It is, thus, quite likely that both the sensible and latent heat fluxes are underestimated under such conditions. 


\section{Conclusions}

The following conclusions can be drawn from the present work:

- The method of estimating the tree biomass storage using trunk and branch temperature measurements seems to give accurate results.

- The tree biomass heat storage is highly significant in relation to other storage fluxes including the soil heat flux in a mature forest.

- The good closure during stable conditions indicate that the flux measurements do indeed function well also during such conditions, i.e., the fluxes are zero or close to zero when they should be so. Nighttime closure is highly dependent on correct estimation of all storage components and in particular the biomass storage since it is the dominating storage flux during nighttime.

- The lack of closure at strongly unstable conditions is a less realized problem, not discussed much in the eddy covariance community. The results indicate that the turbulent fluxes are underestimated during such conditions although the reasons are unclear; it is either a measurement problem related to the large attack angles of the wind vector during strong instabilities or it is related to large eddies not captured by the eddy-covariance system. In any case this problem will also have implications for measurements of other scalars such as, e.g., $\mathrm{CO}_{2}$.

Acknowledgements. This analysis was made within the framework of the Nordic centre for studies of ecosystem carbon exchange and its interactions with the climate system, the NECC (www.necc.nu). The Nordic Council of Ministers and the NOS-N are acknowledged for the financial support.

Edited by: T. Vesala

\section{References}

Abramowitz, M. and Stegun, I. A.: Handbook of mathematical functions, National Bureau of Standards, Applied Mathematics Series, 55, 1046 pp., 1965.

Anonymous: Praktisk Skogshandbok, Sveriges Skogsvårdsförbund, Djursholm, 510 pp., 1994.

Aston, A. R.: Heat storage in a young Eucalypt forest, Agr. Forest Meteorol., 35, 281-297, 1985.

Aubinet, M., Grelle, A., Ibrom, A., Rannik, Ü., Moncrieff, J., Foken, T., Kowalski, A. S., Martin, P. H., Berbigier, P., Bernhofer, C., Clement, R., Elbers, J., Granier, A., Grunwald, T., Morgenstern, K., Pilegaard, K., Rebmann, C., Snijders, W., Valentini, R., and Vesala, T.: Estimates of the annual net carbon and water exchange of forests: The EUROFLUX methodology, Adv. Ecol. Res., 30, 113-175, 2002.

Barr, A. G., Morgenstern, K., Black, T. A., McCaughey, J. H., and Nesic, Z.: Surface energy balance closure by the eddycovariance method above three boreal forest stands and implications for the measurement of the $\mathrm{CO}_{2}$ flux, Agr. Forest Meteorol., 140, 322-337, 2006.

Cava, D., Contini, D, Donateo, A., and Martano, P.: Analysis of short-term closure of the surface energy balance above short vegetation, Agr. Forest Meteorol., 148, 82-93, 2008.

Foken, T.: The energy balance closure problem: An overview, Ecol. Appl., 18(6), 1351-1367, 2008.

Gash, J. H. C. and Dolman, A. J.: Sonic anemometer (co)sine response and flux measurement I., The potential for (co)sine error to affect sonic anemometer-based flux measurements, Agr. Forest Meteorol., 119, 195-207, 2003.

Foken, T., Wimmer, F., Mauder, M., Thomas, C., and Liebethal, C.: Some aspects of the energy balance closure problem, Atmos. Chem. Phys., 6, 4395-4402, 2006, http://www.atmos-chem-phys.net/6/4395/2006/.

Grelle, A.: Long term water and carbon dioxide fluxes from a boreal forest, Acta Universitatis Agriculturae Sueciae, Silvestria 28, 80 pp., 1994.

Grelle, A. and Lindroth, A.: Eddy-correlation system for long term monitoring of fluxes of heat, water vapour, and $\mathrm{CO}_{2}$, Glob. Change Biol., 2, 297-307, 1996.

Håkansson, J. and Körling, A.: Uppskattning av mängden kol i trädform - en metodstudie, Department of Physical Geography, Lund University, Diploma Thesis No. 86, 2002.

Guyot, G.: Physics of the Environment and Climates, John Wiley \& Sons Ltd, 1998.

Halldin, S. and Lindroth, A.: Errors in net radiometry: Comparison and evaluation of six radiometer designs, J. Atmos. Ocean. Tech., 9(6), 762-783, 1992.

Kanda, M., Inagaki, A., Letzel, M. O., Raasch, S., and Watanabe, T.: LES studies of the energy imbalance problem with eddy covariance fluxes, Boundary-Layer Meteorology, 110, 381-404, 2004.

Lee, X.: On micrometeorological observations of surface-air exchange over tall vegetation, Agr. Forest Meteorol., 91, 39-50, 1998.

Lundblad, M. and Lindroth, A.: Transpiration of a coniferous forest in relation to weather and stand characteristics, Basic Appl Ecol., 3, 229-243, 2002.

Lundin, L. C., Cienciala, E., Grelle, A., Halldin, S., Hjelm, P., Kellner, E., Lindroth, A., Mölder, M., Lundberg, A., Moren, A.-S., Nord, T., Seibert, J., and Stähli, M.: Continuous long-term measurements of soil-plant-atmosphere variables at a forest site, Agr. Forest Meteorol., 98-99, 53-74, 1999.

Massman, W. J. and Lee, X.: Eddy covariance flux corrections and uncertainties in long-term studies of carbon and energy exchanges, Agr. Forest Meteorol., 113, 121-144, 2002.

McCaughey, J. H. and Saxton, W. L.: Energy balance storage terms in a mixed forest, Agr. Forest Meteorol., 44, 1-18, 1988.

McCaughey, J. H., Lafleur, P. M., Joiner, D. W., Bartlett, P. A., Costello, A. M., Jelinski, D. E., and Ryan, M. G.: Magnitudes and seasonal patterns of energy, water and carbon exchanges at a boreal young jack pine forest in the BOREAS northern study area, J. Geophys. Res., 102(D24), 28997-29007, 1997. 
Meesters, A. G. C. A. and Vugts, H. F.: Calculation of heat storage in stems, Agr. Forest Meteorol., 78, 181-202, 1996.

Moderow, U., Aubinet, M., Feigenwinter, C., Kolle, O., Lindroth, A., Mölder, M., Montaganai, L., Rebman, C., and Bernhofer, C.: Available energy and energy balance closure at four coniferous forest sites across Europe, Theor. Appl. Climatol., 98, doi:10.1007/s00704-009-0175-0, 2010.

Moore, C. J. and Fisch, G.: Estimating heat storage in Amazonian tropical forest, Agr. Forest Meteorol., 38, 147-169, 1986.

Mölder, M., Lindroth, A., and Halldin, S.: Water vapor, $\mathrm{CO}_{2}$, and temperature profiles in and above a forest - accuracy assessment of an unattended measurement system, J. Atmos. Ocean. Technol., 17(4), 417-425, 2000.

Näslund, M.: Functions and tables for computing the cubic volume of standing trees, Meddelanden från Statens skogsforskningsinstitut, 36, 3, Stockholm, 81 pp., 1947.

Oliphant, A. J., Grimmond, C. S. B., Zutter, H. N., Schmid, H. P., Su, H.-B., Scott, S. L., Offerle, B., Randolph, J. C., and Ehman, J.: Heat storage and energy balance fluxes for a temperate deciduous forest, Agr. Forest Meteorol., 126, 185-201, 2004.

Paw, U. K. T., Baldocchi, D., Meyers, T. P., and Wilson, K. B.: Correction of eddy-covariance measurements incorporating both advection effects and density fluxes, Agr. Forest Meteorol., 97, 487-511, 2000.

Roupsard, O., Bonnefond, J.-M., Irvine, M., Berbigier, P., Nouvellon, Y., Dauzat, J., Taga, S., Hamel, O., Jourdan, C., Saint-Andre, L., Mialet-Serra, I., Labouisse, J.-P., Epron, D., Joffre, R., Braconnier, S., Rouziere, A., Navarro, M., and Bouillet, J.-P.: Partitioning energy and evapo-transpiration above and below a tropical palm canopy, Agr. Forest Meteorol., 139, 252-268, 2006. dos Santos Michiles, A. A. and Gielow, R.: Above-ground thermal energy storage rates, trunk heat fluxes and surface energy balance in a central Amazonian rainforest, Agr. Forest Meteorol., 148, 917-930, 2008.

Schmid, H. P.: Experimental design for flux measurements: matching scales of observations and fluxes, Agr. Forest Meteorol., 87, 179-200, 1997.

Tanaka, H., Hiyama, T., Kobayashi, N., Yabuki, H., Ishii, Y., Desyatkin, R. V., Maximov, T. C., and Ohta, T.: Energy balance and its closure over a young larch forest in eastern Siberia, Agr. Forest Meteorol., 148, 1954-1967, 2008.

Twin, T. E., Kustas, W. P., Norman, J. M., Cook, D. R., Houser, P. R., Meyers, T. P., Prueger, J. H., Starks, P. J., and Wesely, M. L.: Correcting eddy-covariance flux estimates over grassland, Agr. Forest Meteorol., 103, 279-300, 2002.

Van der Molen, M. K., Gash, J. H. C., and Elbers, J. A.: Sonic anemometer (co)sine response and flux measurement II. The effect of introducing an angle of attack dependent calibration, Agr. Forest Meteorol., 122, 95-109, 2004.

Wilson, K., Goldstein, A., Falge, E., Aubinet, M., Baldocchi, D., Berbigier, P., Bernhofer, C., Ceulemans, R., Dolman, H., Field, C., Grelle, A., Ibrom, A., Law, B. E., Kowalski, A., Meyers, T., Moncrieff, J., Monson, R., Oechel, W., Tenhunen, J., Valentini, R., and Verma, S.: Energy balance closure at FLUXNET sites, Agr. Forest Meteorol., 113, 223-243, 2002.

Wolf, A., Saliendra, N., Akshalov, K., Johnson, D. A., and Laca, E.: Effects of different eddy covariance correction schemes on energy balance closure and comparison with the modified Bowen ratio system, Agr. Forest Meteorol., 148, 942-952, 2008. 